\title{
Does Uncovered Interest Rate Parity Hold After All?*
}

\section{Muhammad Omer ${ }^{* *}$, Jakob de Haan ${ }^{* * *}$ and Bert Scholtens ${ }^{* * * *}$}

\begin{abstract}
This paper tests Uncovered Interest Rate Parity (UIP) using LIBOR rates for six major international currencies for the period January 2001 to December 2008. We find that UIP generally holds over a short-term (above 5-months) horizon for individual as well as groups of currencies. Our results suggest that it is important to consider the cross-correlation between currencies. We also find that "state dependence" plays an important role for currencies with a negative interest rate differential vis-à-vis the US dollar. This state dependence could also be instrumental in explaining exchange rate overshooting.
\end{abstract}

Keywords: UIP, LIBOR, system SUR, system DGLS, system DOLS.

JEL Classification: G12, G15, F31.

\section{Introduction}

Uncovered interest rate parity (UIP) suggests that any arbitrage opportunity between interest-earning assets of different economies but with similar characteristics, will disappear due to exchange rate movements. A positive shock to the domestic interest rate vis-à-vis the foreign interest rate will lead to the depreciation of the home currency and vice versa. UIP plays a critical role in most exchange rate determination theories, such as the monetary exchange rate model, Dornbusch's (1976) overshooting model and Krugman's (1991) target zone model. Also, central banks frequently count on this relationship in order to anchor exchange rate expectations in the economy (Kalyvitis \& Skotida, 2010).

\footnotetext{
* The views expressed in the paper are solely of authors and have nothing to do with the State Bank of Pakistan or De Nederlandsche Bank. Moreover, authors are solely responsible for any unintentional error or omission, if they remain in this paper.

** University of Groningen, Faculty of Economics and Business, PO Box 800, 9700 AV Groningen, The Netherlands.

*** University of Groningen, Faculty of Economics and Business, PO Box 800, 9700 AV Groningen, The Netherlands. De Nederlandsche Bank, PO Box 98, 1000 AB Amsterdam, The Netherlands. CESifo, Munich, Germany

***** University of Groningen, Faculty of Economics and Business, PO Box 800, 9700 AV Groningen, The Netherlands.
} 
It is surprising that theorists continue to rely on UIP despite ambiguous (at best) empirical support. Several studies (Bekaert \& Hodrick, 1993; Engel, 1996; Froot \& Thaler, 1990; Mark \& Wu, 1998; Weber, 2011; Tang, 2011), to mention just a few, reject UIP. Only a few studies report some support for UIP, including Flood \& Rose (1996), Bekaert and Hodrick (2001), Baillie and Bollerslev (2000), Chaboud and Wright (2005) and Beyaert et al. (2007).

Given the crucial role played by UIP in exchange rate theory and exchange rate stabilization policy, this relationship warrants more detailed investigation. Evidence supporting UIP will not only increase confidence in the existing exchange rate models but may also enhance the quality of monetary policy decision-making. This paper is an effort in this direction.

This paper extends the existing UIP literature by focusing on important issues affecting this relationship. First, we use a multi-currency setup to make use of cross currency correlation. Some previous studies using Seemingly Unrelated Regression (SUR), such as Flood \& Rose (1996) and Mark \& Wu (1998), have exploited cross currency correlations. However, most studies investigate UIP mainly bilaterally. In our view, bilateral studies implicitly impose restrictions on the third-country effect, which may play an important role in determining exchange rates. This is equally true for studies using a panel data setup that ignores cross sectional dependence. In a globalized world, any shock to the US debt market say, will not only affect the Japanese debt market but also the euro debt market. Therefore, an interest rate shock in the US will not only affect the US dollar and the Japanese yen exchange rate or the US dollar and the euro exchange rate, but also the euro-yen exchange rate. Studies on UIP have mostly ignored this cross currency correlation.

Second, we use data for industrial economies as the literature suggest that, for these countries, the problem of a forward premium puzzle is more prominent (see Alper et al., 2009; Bansal, 1997; Bansal \& Dahlquist, 2000). For developing and emerging market economies, the empirical evidence provides more support for UIP (see, for example, Frankel \& Poonawala, 2010; Ferreira \& Leon-Ledesma, 2007; Flood \& Rose, 2001; Bansal \& Dahlquist, 2000).

Third, rather than using domestic interest rates, we use the London Interbank Offered Rates (LIBOR). LIBOR is an indicative interbank rate for specific currencies based on the non-binding quotes in the London 
interbank market. ${ }^{1}$ LIBOR rates are widely used as benchmarks in global financial transactions and provide a framework where several known frictions, such as imperfect capital mobility and differences in transaction costs explaining the failure of UIP, are absent. ${ }^{2}$

The statistical evaluation supports LIBOR as a substitute for domestic interest rates. Factor analysis shows that the LIBOR rates are defined by only one factor, i.e. domestic interest rates, suggesting that our results are not driven by the use of LIBOR. ${ }^{3}$ Still, using LIBOR has several advantages. For instance, the currency specific LIBOR rates have similar transaction costs for the assets denominated in various currencies, while capital is perfectly mobile. Juselius and MacDonald (2004), Harvey (2004) and Ichiue and Koyama (2011) have used LIBOR as a proxy for Japanese domestic rates, arguing that the thin and heavily regulated Japanese money market in the 1980s and 1990s was less reflective of Japan's economic fundamentals.

Finally, following a suggestion of Moon and Perron (2005), we take as our null hypothesis that UIP holds; that is, the slope coefficient is unity. Often the null hypothesis tested is that the slope coefficient is not different from zero, which on rejection provides support for the alternative hypothesis that the slope coefficient is in fact different from zero. According to Moon and Perron (2005), such a test design has a strong bias towards the null hypothesis, which is rejected only when there is strong support against it. Moreover, when the null of a zero slope coefficient cannot be rejected, it is difficult to conclude whether the theory is rejected or the power of the test is low.

Our estimates using weekly data for the period January 2001 to December 2008 support UIP over the short-term (above 5-months) horizon for currencies from advanced countries. Further, our currency specific estimates show that the null hypothesis of a unit coefficient can generally not be rejected at the 5 percent level of significance. However, for the Japanese yen and the Swiss franc, the slope coefficients are negative. This finding is consistent with the argument put forward by Bansal and

\footnotetext{
${ }^{1}$ For details see Michaud and Upper (2008).

${ }^{2}$ Forbes Investopedia estimates that $\$ 360$ trillion worth of international financial products are benchmarked with LIBOR. Additionally, one trillion dollars of sub-prime mortgages have rates adjustable to LIBOR.

${ }^{3}$ Factor analysis is a widely used technique for summarizing usually a large number of variables with a small number of factors. For the sake of brevity, we do not report the results of the factor analysis but they are available on request.
} 
Dahlquist (2000) and Ballie and Kalic (2006) that deviations from UIP appear when the US interest rate exceeds the foreign interest rate, called "state dependence". Once we incorporate the negative interest rate differential, UIP cannot be rejected for the Japanese yen and the Swiss franc. Our results show that cross currency effects play an important role in determining the exchange rate between currencies. Finally, we also find some support for Dornbusch's (1976) overshooting hypothesis for exchange rates, specifically for the Japanese yen and the Swiss franc against the US dollar, suggesting that state dependence could also be instrumental in explaining exchange rate overshooting.

The rest of the paper is structured in the following way. Section 2 reviews the literature. Section 3 delves into data and methodology issues, while section 4 presents results. Finally, section 5 offers conclusions of the paper.

\section{Literature Review}

According to the Covered Interest Rate Parity (CIP) hypothesis, under risk free arbitrage the ratio of the forward to the spot exchange rate will be equal to the ratio of the returns on two similar assets, measured in the local currencies. Expressing the forward and spot rates in logarithms, CIP can be written as:

$$
\left(f_{t, t+i}-S_{t}\right)=\left(r_{i, t}-r_{i, t}^{*}\right)
$$

where $f_{t, t+i}$ is the forward rate for maturity $i, s_{t}$ is the spot exchange rate, $r_{i, t}$ and $r_{i, t}^{*}$ are the nominal return at any time $t$ for maturity $i$ on a domestic and foreign asset, respectively. However, if forward rates deviate from the expected future spot rate, a risk premium is required such that:

$$
\left[E\left(S_{t, t+i}\right)-S_{t}\right]=\alpha+\left(r_{i, t}-r_{i, t}^{*}\right)
$$

where $\alpha$ is the risk premium and $E\left(S_{t, t+i}\right)$ is the expected future exchange rate at time $t+i$. Under UIP, the risk premium is zero and the coefficient of the interest differential is one. Since the future spot exchange rates cannot be observed directly, UIP is generally tested jointly with the assumption of rational expectations in the exchange rate market (Chinn, 2007):

$$
\left[R E\left(S_{t+i}\right)-S_{t}\right]=\alpha+\beta\left(r_{i, t}-r_{i, t}^{*}\right)+\varepsilon_{t+i}
$$


Following studies such as Tang (2011), Bekaert et al. (2007), Chinn and Meredith (2004), and Carvalho et al. (2004), we assume that agents have perfect foresight so that exchange rate movements can be estimated using equation (4):

$$
\left[S_{t+i}-S_{t}\right]=\alpha+\beta\left(r_{i, t}-r_{i, t}^{*}\right)+\varepsilon_{t+i}
$$

Most studies on UIP report a negative point estimate for the beta coefficient, $\beta$, over the short-term horizon (see Froot \& Thaler, 1990; MacDonald \& Taylor, 1992; McCallum, 1994; Engel, 1996; Chin \& Meredith, 2004; Isard, 2006; Chinn \& Quayyum, 2012). A notable exception is Flood and Rose (1996), who report a slope coefficient close to one during the period with exchange rate alignments within Europe's Exchange Rate Mechanism (ERM). Other studies, such as Bruggemann and Lutkepohl (2005), Huisman et al. (1998), and Krishna Kumar and Neto (2008) provide indirect support for UIP. More precisely, Huisman et al. (1998) have shown that the large forward premium provides an unbiased estimate of the future change in the spot rate while a small forward premium fails to predict the same correctly. Bruggemann and Lutkepohl (2005), and Krishna Kumar and Neto (2008) have tested UIP jointly with the expectation hypothesis of the term structure (EHT) using interest rates of the respective economies. By assuming that exchange rates are generated by a stationary process they provided evidence in support of UIP using the stationarity of the interest rate differential.

Bansal (1997) reports that the failure of UIP is more severe for industrial economies compared to developing economies. In addition, Bansal and Dahlquist (2000) and Baillie and Kilic (2006) point to state dependence in the UIP relationship, i.e. the exchange rate denominated in the US Dollar responds differently to the positive or negative interest rate differentials. More specifically, deviations from UIP appear only when the US interest rate exceeds the foreign interest rate. When the foreign interest rate exceeds the US interest rate, the expected depreciation and the increase in interest rate differentials are positively related.

Several studies have tested UIP bilaterally, thereby implicitly imposing restrictions on the third economy's effect. Moreover, this restriction might have fostered non-linearities in the UIP relationship, a subject investigated by a different strand of literature. ${ }^{4}$ Studies using

\footnotetext{
${ }^{4}$ Studies discussing non-linearities in UIP include Baldwin (1990), Dumas (1992), Sercu and Wu (2000), Lyons (2001), Kilian and Taylor (2003), and Carlson and Osler (1999).
} 
panel data techniques and ignoring the cross currency effect suffer from similar problems.

Chinn and Meredith (2004) note that UIP models by construction have cross-equation correlation of the error terms and therefore techniques incorporating cross currency correlations such as SUR are appropriate. Two studies, Flood and Rose (1996) and Mark and Wu (1998), have employed SUR to control for cross currency correlations. However, the outcomes of both studies are very different. While Flood and Rose (1996) report a slope coefficient close to one during the period with exchange rate alignments within Europe's ERM, Mark and Wu (1998) do not find strong support for UIP.

To control for the cross-equation correlation, both studies employ SUR based on OLS, but using the contemporaneous covariance matrix. A contemporaneous covariance matrix uses current information only, ignoring long-run relationships which may be misleading if there exists such a long-run relationship.

Importantly, when regressors are integrated, indicating a long-run relationship between them, Moon and Perron (2005) have shown that the limiting distributions of OLS estimators are not normal. To solve this problem, they propose augmenting the regressors with their leads and lags to capture the long-run correlation. In addition, they argue for using the long-run covariance matrix instead of the contemporaneous covariance matrix, which enhances the efficiency gain of the long-run estimators. This paper therefore uses SUR with integrated regressors as proposed by Moon and Perron (2005).

More recently, Omer et al. (2014), and Ismailov and Rossi (2018) tested UIP over a short horizon for advanced economies. Precisely, Omer et al. (2014) has tested uncovered interest rate parity (UIP) using LIBOR interest rates by controlling the cross currency correlation similar to this study. They have reported that UIP holds for several short-term maturities for advanced economies. Their estimates, as discussed by these authors, were aggregate in the sense that the bilateral relationships between the currencies could not be explored due to procedural limitations. This study, is therefore an extension of Omer et al. (2014), and estimates beta coefficients for the individual currencies in a correlated currency environment by adopting a more suitable procedure proposed by Moon and Perron (2005). 
Similar to Omer et al. (2014), Ismailov and Rossi (2018) have investigated UIP for currencies except for the Australian dollar, and using 3-month Euribor (Euro Interbank Offered Rate) only. Euribor is an average interest rate at which a large panel of European banks borrow funds from one another in the European interbank market. Besides the familiar currency and interest rate setup, they have constructed an exchange rate uncertainty index to measure any uncertainty in support of their empirical evidence. Their findings suggest that uncovered interest rate parity does hold in five industrialized countries vis-à-vis the US dollar at times when uncertainty is not exceptionally high. However, this relationship breaks down during high periods of uncertainty.

\section{Data and Methodology}

\subsection{Data}

Our sample period is January 2001 - December 2008. ${ }^{5}$ We use the following currencies: the Euro, the Japanese yen, the British pound, the Australian dollar, the Canadian dollar, and the Swiss franc against the US dollar. We have acquired daily data on the exchange rates from the International Monetary Fund (IMF). ${ }^{6}$ For the interest rates, we use daily LIBOR rates for the above currencies with short maturities. The LIBOR interest rates data can be accessed from the British Bankers Association (BBA) website.7 Exchange rate differentials are calculated assuming that economic agents have perfect foresight. So the -month exchange rate differential series, for example, is calculated by subtracting the current spot rate from the spot rate after six months. Similarly, to generate interest rate differentials we subtract the currency-and maturity-specific LIBOR from the US dollar LIBOR with similar maturity. In view of the outcomes of unit root tests (to be discussed below), we use maturities ranging from 6 to 12 months.

From daily data we have calculated weekly and monthly data. ${ }^{8}$ Figure 1 shows the 6-month interest rate differential for all currencies. Other

\footnotetext{
${ }^{5}$ Extending our sample would involve structural break issues. The introduction of the euro, as a single European currency in January 1999, has brought structural changes in the global financial system. In order to make sure that our results are not driven by these changes, we did not include 1999 and 2000. Our sample ends in 2008 in view of the global financial crisis that started in late 2008 with the fall of the Lehman Brothers. In our view, a financial crisis may distort an economic relationship which exists under stable normal circumstances.

${ }^{6} \mathrm{http} / / / \mathrm{www} . i m f . o r g /$ external/np/fin/data/param_rms_mth.aspx.

${ }^{7} \mathrm{http}: / /$ www.bbalibor.com/rates/historical.

${ }^{8}$ Weekly averages are calculated using five working days. This procedure leads to an overlapping data problem as indicated by the Harri and Brorsen (2009). However, as the long-run covariance
} 
maturities show more or less similar variation. Figure 1 shows that these series follow similar patterns, and hence are highly positively correlated (see Panel A of Table A1 in the Appendix for the correlation between the first differenced of these series). Importantly, both the Japanese yen and the Swiss franc have negative interest rate differentials since the US dollar LIBOR rates are higher than these currency specific rates.

\section{Figure 1: Movement in 6-Month Interest Rate Differentials}

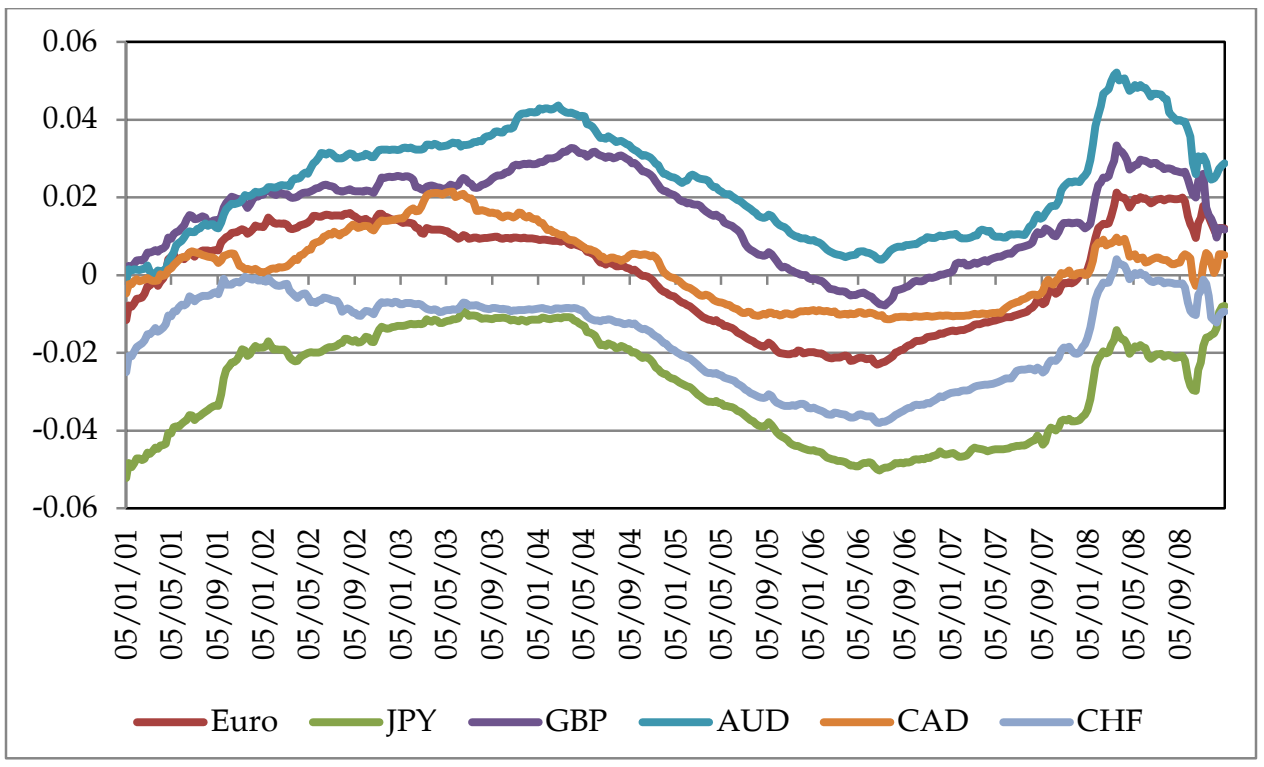

Source: Authors' Calculations

\subsection{Methodology}

Since our dataset involves a long time series, it is essential to ascertain the nature of the data- generating process of the regressors. Therefore, we have applied unit root tests.

Previous studies generally adopted unit root tests, such as the Augmented Dickey Fuller (ADF) or Phillip and Perron (PP) tests, but these time series tests are limited in scope in the presence of cross correlation effects. Therefore, we apply the Cross-sectional Dependence Robust Block Bootstrap (CDRBB) panel unit roots test proposed by Palm et al. (2011). 
The CDRBB unit root test does not require modeling the temporal or cross-sectional correlation (dependence) structure between the currency-specific interest rates. Moreover, it uses block bootstrap techniques, a time series version of a standard bootstrap where the dependence structure of the time series is preserved by dividing data into blocks and then re-sampling the blocks. However, the block length selected can have a large effect on the performance of any designed block bootstrap test. Inferences from the CDRBB test are valid under a wide range of possible data-generating processes, which makes it an appropriate tool in dealing with the fixed number of correlated cross-sections and large time series asymptotics.

Although this CDRBB test provides both "pooled" $\left(\tau_{p}\right)$ and "groupmean" $\left(\tau_{g m}\right)$ test statistics, we only show the outcomes for the group mean statistics here (while the pooled statistics are shown in the Appendix). The group mean statistic does not impose restrictions on individual parameters, which is more relevant for the analysis at hand. The null hypothesis assumes that the variable is non-stationary while under the alternative hypothesis a part of the series is stationary. Rejection of the null hypothesis for the first difference of a variable and non-rejection for the level of the same variable indicates that the variable concerned has a unit root.

In equation (5), $y_{t}$ is the variable tested for unit roots, $N$ is the number of currencies and $T$ is the sample period:

$$
\tau_{g m}=\frac{1}{N} \sum_{i=1}^{N} T \frac{\sum_{t=2}^{T} y_{i, t-1} \Delta y_{i, t}}{\sum_{t=2}^{T} y_{i, t-1}^{2}}
$$

Next, we apply Johansen's (1995) cointegration test as well as Westerlund's (2007) ECM based panel cointegration test. The former, being the "individual" time series test, has limited application when there are cross correlation effects, while the latter takes those effects into account. For brevity, we will only report the results of Westerlund's (2007) ECM based cointegration tests.

Westerlund (2007) suggests a panel cointegration test based on the error correction mechanism (ECM) as indicated by Eq. (6): 


$$
\Delta y_{i t}=\delta_{i} d_{t}+\alpha_{i}\left(y_{i, t-1}-\beta_{i}^{\prime} x_{i, t-1}\right)+\sum_{j=1}^{p_{i}} \gamma_{1 i j} \Delta y_{i, t-j}+\sum_{j=0}^{p_{i}} \gamma_{2 i j} \Delta x_{i, t-j}+u_{i t}
$$

Here, $d_{i}$ is the currency-specific deterministic component, $\delta_{i}$ is the associated parameter, $\alpha_{i}$ is the speed of adjustment for the error correction term, $\beta_{i}$ is the cointegrating vector while $x_{i t}$ and $y_{i t}$ are interest and exchange rate differentials series, respectively. The choice of the appropriate number of leads and lags, given by $p_{i}$, using information selection criteria, such as Akaike's Information Criterion (AIC), transforms $u_{i t}$ into white noise.

The null hypothesis of the cointegration test is $\alpha_{i}=0$, which indicates no cointegration of the variables. The alternative hypotheses depend on the homogeneity assumption of $\alpha_{i}$ and have four different versions. Two of the tests are termed as "group mean tests $\left(G_{\alpha}\right.$ and $\left.G_{\tau}\right)$ " since they do not require $\alpha_{i}$ to be equal. The other two are known as "pooled tests $\left(P_{\alpha}\right.$ and $\left.P_{\tau}\right)$ " as they assume equal $\alpha_{i}$ for all the members of the panel. For the sake of brevity we will present the group mean test statistics $\left(G_{\alpha}\right.$ and $\left.G_{\tau}\right)$ only (while the other test outcomes are shown in the Appendix). The group mean statistics differ in composition. Whereas $G_{\alpha}$ is calculated by aggregating the individual slope coefficients with the help of conventional standard errors, $G_{\tau}$ is designed by aggregating the individual slope coefficients using Newey and West (1994) long-run standard errors. The alternative hypothesis for the group mean test is that at least one member of the panel is cointegrated. Simulation results of Westerlund (2007) show that $G_{\alpha}$ has a higher power compared to $G_{\tau}$ in samples where $\mathrm{T}$ is substantially larger than $\mathrm{N}$. Asymptotically, both statistics have a limiting normal distribution, and they are consistent. Moreover, Westerlund's (2007) procedure provides robust critical values for the test statistics by applying bootstrapping which accounts for the cross sectional dependence.

For drawing inference on long-run relationships, we use Moon and Perron's (2005) efficient estimation method of a system of SUR equations with integrated regressors. This method provides more efficient estimates by exploiting the correlations among multiple currencies while allowing for individual currency-specific inferences. Conventional system estimation methods, such as GLS, with integrated regressors have a nonstandard limiting distribution that is skewed and shifted away from the true parameters. This renders inference difficult. Moon and Perron (2005) suggest a method for obtaining efficient estimators with a mixed normal limiting distribution. By adding the leads and lags of the first 
differences of the regressors, they suggest applying GLS on this augmented dynamic regression model using information on the long-run covariance matrix, hence its name: System Dynamic GLS (SDGLS).

The Monte Carlo simulation results of Moon and Perron (2005) show that SDGLS performs better compared to other estimators. ${ }^{9}$ Moreover, the efficiency gain of the SDGLS estimates is greater compared to other estimates obtained in similar fashion. Furthermore, the SDGLS estimator suffers least from distortion due to a small sample. Based on its superior performance, we utilize the SDGLS estimator.

Equation (7) shows the SDGLS estimator using the multivariate format of SUR:

$$
\begin{aligned}
\hat{b}_{D G L S}= & \left(\sum_{t=k+1}^{T-k} Z_{t} \widehat{\Omega}_{u u . v}^{-1} Z_{t}^{\prime}\right)^{-1}\left(\sum_{t=k+1}^{T-k} Z_{t} \widehat{\Omega}_{u u . v}^{-1} y_{t}\right)= \\
& b+\left(\sum_{t=k+1}^{T-k} Z_{t} \widehat{\Omega}_{u u . v}^{-1} Z_{t}^{\prime}\right)^{-1}\left(\sum_{t=k+1}^{T-k} Z_{t} \widehat{\Omega}_{u u . v}^{-1} \xi_{t}^{*}\right)
\end{aligned}
$$

Here, $b$ is the matrix of coefficients of regressors and the leads and lags of the first difference of the regressors, $Z_{t}=\left(\tilde{x}_{t}^{\prime}, \Delta x_{t-k}^{\prime} \otimes I_{N}, \ldots, \Delta x_{t+k}^{\prime} \otimes\right.$ $\left.I_{N}\right)^{\prime}, \tilde{x}_{t}^{\prime}=\operatorname{diag}\left(\tilde{x}_{1 t}, \ldots, \tilde{x}_{N t}\right), \tilde{x}_{i t}=\left(1, x_{i t}^{\prime}\right), x_{i t}=\left(x_{i t}^{\prime}, \ldots, x_{N t}^{\prime}\right)^{\prime}, \xi_{t}^{*}$ is the error term with the non-estimable part of regressors beyond $k$. The null hypothesis tests whether the individual slope coefficient $(b)$ is unity, or in other words whether UIP holds on a currency-specific basis.

This direct test of UIP differs from the usual testing methodology in which the null hypothesis is that the coefficient is not different from zero. According to Moon and Perron (2005), such a test design has a strong bias towards the null hypothesis which also affects the interpretation of the test results in an undesirable way. When the null hypothesis cannot be rejected, it is hard to determine whether the theory is rejected or the power of the test is low. Another advantage of the Moon and Perron test design is that it does not require testing cointegration separately. If the error term is nonstationary for any of the model coefficients, the test statistics diverge to infinity, thereby rejecting the null hypothesis that UIP holds. This alternative test for cointegration based on the coefficient of the

\footnotetext{
${ }^{9}$ Using their proposed method based on the SUR technique Moon and Perron (2005) have suggested a number of estimators such as system dynamic OLS (SDOLS) or fully modified OLS (FMOLS), besides the dynamic GLS estimator. The system dynamic OLS (SDOLS), is given by:

$$
\hat{b}_{S D O L S}=\left(\sum_{t=k+1}^{T-k} Z_{t} Z_{t}^{\prime}\right)^{-1}\left(\sum_{t=k+1}^{T-k} Z_{t} y_{t}\right)=b+\left(\sum_{t=k+1}^{T-k} Z_{t} Z_{t}^{\prime}\right)^{-1}\left(\sum_{t=k+1}^{T-k} Z_{t} \xi_{t}^{*}\right)
$$

Notations have the same meaning as in equation (7). Both estimators $\hat{b}_{S D O L S}$ and $\hat{b}_{D G L S}$ use the longrun correlation information of the system.
} 
cointegrating vector is more powerful than simple cointegration tests (Cheung \& Lai, 1993).

\section{Results}

Table 1 reports the group mean CDRBB panel unit root tests. For both the interest and the exchange rate differential series, at maturities of six months and higher, the null hypothesis of a unit root cannot be rejected at the 5 percent level of significance, indicating that the level of these series are non-stationary. A test on the first differences of these series confirms that these maturities are following an I (I) process (not reported for brevity). The pooled test statistics yield similar results (see Table A2 in the Appendix). In the rest of the paper, we will therefore focus on maturities of 6 months and longer.

\section{Table 1: Block Bootstrap Panel Unit Root Tests}

\begin{tabular}{|c|c|c|c|c|c|c|}
\hline & \multicolumn{3}{|c|}{$\begin{array}{c}\text { Exchange Rate Differential Series } \\
5 \text { percent }\end{array}$} & \multicolumn{3}{|c|}{$\begin{array}{c}\text { Interest Rate Differential Series } \\
5 \text { percent }\end{array}$} \\
\hline & Statistics & $\mathrm{CV}$ & P-value & Statistics & $\mathrm{CV}$ & P-value \\
\hline 1-week & -314.7570 & -19.1730 & 0.0000 & -3.9440 & -17.7150 & 0.8750 \\
\hline 2-week & -166.1620 & -23.6380 & 0.0000 & -2.8860 & -13.9870 & 0.8540 \\
\hline 1-month & -69.8510 & -20.6940 & 0.0000 & -2.1160 & -9.9800 & 0.7900 \\
\hline 2-month & -32.0290 & -14.4190 & 0.0000 & -2.1880 & -8.2040 & 0.6890 \\
\hline 3-month & -19.1170 & -12.1780 & 0.0020 & -2.2870 & -7.9620 & 0.6490 \\
\hline 4-month & -12.6120 & -12.3460 & 0.0450 & -2.2060 & -7.2350 & 0.6480 \\
\hline 5-month & -8.1130 & -11.9260 & 0.2340 & -2.1610 & -6.8740 & 0.6570 \\
\hline 6-month & -6.9340 & -11.4470 & 0.3370 & -2.1540 & -6.7890 & 0.6620 \\
\hline 7-month & -6.5470 & -12.1160 & 0.4220 & -2.1300 & -6.8150 & 0.6820 \\
\hline 8-month & -5.7180 & -12.1480 & 0.5700 & -2.0930 & -6.9130 & 0.7060 \\
\hline 9-month & -5.9400 & -12.4110 & 0.6010 & -2.0780 & -7.0330 & 0.7270 \\
\hline 10-month & -5.7460 & -13.2370 & 0.6740 & -2.0730 & -7.1480 & 0.7420 \\
\hline 11-month & -5.5980 & -13.2420 & 0.6330 & -2.1030 & -7.3280 & 0.7520 \\
\hline 12-month & -5.8910 & -13.0600 & 0.5870 & -2.1220 & -7.5120 & 0.7690 \\
\hline
\end{tabular}

Source: Authors' Calculations.

Note: Estimated test statistics for equation (5) for exchange rate and interest rate differential series. 5 percent $\mathrm{CV}$ indicates robust critical values calculated at 5 percent level of significance. P-values indicate the corresponding probability values of the calculated test statistics.

Next, we apply the Johansen (1995) cointegration tests on individual currency-specific time series. The results do not provide any evidence for a cointegration relationship between interest and exchange rate series (results available on request). In contrast, the Westerlund (2007) ECM based panel cointegration tests as shown in Table 2 indicate that the 
null hypothesis of no cointegration is rejected for maturities ranging between 6 and 9 months at the 5 percent level of significance. The results indicate that at least one member of the panel is cointegrated for these maturities. For the other maturities, the evidence for "no cointegration" is rather weak as the rejection probabilities ( $p$-values) are very low. So our results suggest that inferences regarding financial market variables based on the Johansen cointegration test can be misleading if cross correlation effects are ignored.

Table 2: Results for the Westerlund Cointegration Test (Group Mean Test)

\begin{tabular}{lccccccc}
\hline & \multicolumn{3}{c}{$G_{\alpha}$} & & \multicolumn{3}{c}{$G_{\tau}$} \\
\cline { 2 - 4 } \cline { 6 - 8 } \cline { 6 - 8 } & Value & Z-value & Rob. P-value & Value & Z-value & Rob. P-value \\
\hline 6-month & -12.2080 & -4.5270 & 0.0000 & & -2.2560 & -3.0120 & 0.0020 \\
7-month & -9.8120 & -3.2370 & 0.0000 & & -1.9260 & -2.2370 & 0.0200 \\
8-month & -8.3590 & -2.4540 & 0.0200 & & -1.7430 & -1.8050 & 0.0540 \\
9-month & -7.6540 & -2.0740 & 0.0360 & & -1.7510 & -1.8240 & 0.0640 \\
10-month & -6.6340 & -1.5250 & 0.0560 & & -1.6230 & -1.5220 & 0.0620 \\
11-month & -5.4670 & -0.8960 & 0.1240 & & -1.4310 & -1.0710 & 0.1440 \\
12-month & -5.3260 & -0.8210 & 0.1220 & -1.4430 & -1.0990 & 0.1240 \\
\hline
\end{tabular}

Source: Authors' Calculations.

Note: Estimates of ECM coefficient based on equation (6). The alternative hypothesis of these test statistics are the cointegration relationship exists when the panel taken as whole. 5 and 12 are the maximum number of leads and lags considered for estimation. Values give the estimated values of the coefficients and Z-values are their standardized values. Rob. Pvalues are the robust probability values calculated using the bootstrap technique. The corresponding values show the level of significance.

As pointed out, the methodology we have adopted here to make inference does not require testing cointegration separately. Therefore, our cointegration results as reported in Table 2 (and Table A3 in the Appendix) should be considered as a robustness check of the system SUR estimates to which we turn now. We have applied SUR on interest and exchange rate differential series for each maturity separately using a maximum of 12 leads or lags. Table 3 shows the estimation results using system DGLS, which includes the individual slope coefficient for each currency vis-à-vis the US Dollar.

The Wald test aggregates the individual currency specific slope coefficient and tests the null hypothesis that the joint slope coefficient is unity. In other words, it tests whether UIP holds for the system of currencies taken together. The reported $\mathrm{p}$-values for Wald test statistics show that the null hypothesis cannot be rejected for maturities ranging 
between 10 and 12-months. Hence, UIP holds for these maturities when all six currencies are taken together. ${ }^{10}$

Table 3: Estimation Results Using System Dgls (SDGLS)

\begin{tabular}{|c|c|c|c|c|c|c|c|}
\hline & 6-m & 7-m & 8-m & 9-m & 10-m & 11-m & 12-m \\
\hline \multirow[t]{2}{*}{ Euro } & 3.0261 & 2.3765 & 3.8135 & $5.1693^{* *}$ & 2.9493 & 2.9231 & 3.2848 \\
\hline & 1.7716 & 1.5452 & 1.8149 & 2.2376 & 2.3597 & 2.8520 & 3.6336 \\
\hline \multirow[t]{2}{*}{ JPY } & $-1.2921^{* *}$ & $-1.1077^{* *}$ & $-1.296^{* *}$ & $-1.5944^{*}$ & $-1.0286^{* *}$ & $-1.6118^{* *}$ & -1.3214 \\
\hline & 1.2585 & 1.2611 & 1.1870 & 1.0759 & 1.0482 & 1.0551 & 1.5769 \\
\hline \multirow[t]{2}{*}{ GBP } & 2.1321 & 0.4204 & 0.4771 & -0.1292 & -0.4108 & 0.1099 & 3.1353 \\
\hline & 1.6566 & 1.3567 & 1.5417 & 1.9650 & 2.3640 & 2.0442 & 2.1757 \\
\hline \multirow[t]{2}{*}{ AUD } & 0.5314 & -0.4379 & 0.6683 & -0.1183 & 1.3554 & 1.9217 & 1.0261 \\
\hline & 1.7308 & 1.6050 & 1.9285 & 2.3469 & 3.1521 & 2.2673 & 2.5794 \\
\hline \multirow[t]{2}{*}{ CAD } & -0.1784 & 1.1095 & 0.0519 & -1.1833 & -0.4472 & 0.0817 & -1.4897 \\
\hline & 1.6382 & 1.9127 & 1.7832 & 1.7276 & 1.6198 & 1.9262 & 2.8642 \\
\hline \multirow[t]{2}{*}{$\mathrm{CHF}$} & $-5.6004^{*}$ & $-3.3885^{*}$ & $-1.8798^{* *}$ & $-1.6504^{* *}$ & $-1.3616^{* *}$ & -1.1008 & -1.5929 \\
\hline & 2.4140 & 1.7692 & 1.5111 & 1.5988 & 1.3264 & 1.7211 & 1.7633 \\
\hline Wald Stats & 17.3979 & 16.0100 & 12.6966 & 19.2999 & 9.3929 & 7.5384 & 7.8070 \\
\hline Wald $p$ & 0.0079 & 0.0137 & 0.0481 & 0.0037 & 0.1527 & 0.2739 & 0.2526 \\
\hline
\end{tabular}

Source: Authors' Calculations.

Note: Estimates of the System DGLS coefficient based on Eq. (7) using average weekly data with maximum leads and lags of 12 weeks. The optimal lag length selected using Bayesian Information Criteria (BIC). The null hypothesis is individual coefficient is unity. The figures in italics show the standard errors. The null hypothesis for the Wald test is the joint beta coefficient of unity. Wald P shows the P-values of the Wald test statistics. The symbols indicates $*,<5$ percent and ${ }^{* *}<10$ percent level of significance, respectively.

For the individual currency-specific results, the conclusion is similar. The null hypothesis of unit slope coefficients cannot be rejected for almost all maturities at the 5 percent level of significance. Only for the 9-months Japanese yen and the 6- and 7-months Swiss franc is the null rejected. The slope coefficient of the Japanese yen and the Swiss franc are persistently negative. However, as pointed out in section 3.1, both currencies have negative interest rate differentials vis-à-vis the US interest rate. Ballie and Kalic (2006), Bansal and Dahlquist (2000) and Bansal (1997) provide evidence that the exchange rate vis-à-vis the US dollar responds differently to positive and negative interest rate differentials. Specifically, Bansal and Dahlquist (2000) argue that the forward premium puzzle is present only when the US interest rate exceeds the foreign interest rate.

Interestingly, for the negative interest rate differential series, any increase in the domestic (Japanese/Swiss) interest rates vis-à-vis the US

\footnotetext{
${ }^{10}$ Estimates from monthly data, as reported in Table A4 of the Appendix, also fail to reject the null hypothesis of the Wald tests for all maturities.
} 
interest rate means a decrease in the differential. Some studies have used the US dollar as domestic currency, instead of the foreign currency, to avoid the negative interest rate differential. In a bilateral environment, the flipping of the exchange rate may work, but it is less likely to work in our multi-currency setup. Panel B of Table A1 (in Appendix) shows the correlations between the (first difference of the) interest rate differential series when the Japanese yen and Swiss franc are taken as numeraire currencies against the US dollar. This flipping of currencies solves the problem of the negative interest rate differential since the US dollar becomes the home currency. However, the correlation structure between the interest rate differential of the various currencies gets significantly distorted. Our estimation with this modified Japanese yen and Swiss franc interest rate setup gives a similar distorted picture of the slope coefficients (results are available on request).

Interestingly, whenever the null hypothesis is rejected in our setup, it implies overshooting/undershooting of exchange rates, consistent with Dornbusch's (1976) exchange rate overshooting hypothesis. According to Frenkel and Rodriquez (1982), the exchange rate overshoots when capital is highly mobile while it undershoots when capital is highly immobile. With LIBOR market rates, we are close to perfect capital mobility. Using a 90 percent confidence level of our interval estimation, we find some evidence of persistent overshooting in line with the view of Frenkel and Rodriquez (1982). For both the Japanese yen and the Swiss franc, the null hypothesis of a unit slope coefficient is rejected at the 10 percent level of significance. However, we find little evidence of overshooting for the other currencies which leads us to suspect that overshooting could be a state dependent phenomenon as well. In other words, when currencies have low interest rates compared to US interest rates, overshooting of the exchange rate becomes a possibility. However, more research is needed to draw strong conclusions.

As a robustness check, Table A5 provides the results for the SDOLS estimator.11 This estimator is the most efficient alongside the DGLS estimator and suffers less from size distortion compared to fully modified estimators. It turns out that the SDOLS estimates are very similar to those reported in Table 3.

Finally, a caveat that has to be made is the high variance of the individual slope coefficients. Fully modified estimators, such as FM-GLS,

\footnotetext{
${ }^{11}$ For the SDOLS estimator: see footnote 9.
} 
show relatively low estimated variances (results are shown in Table A6) but these estimators are less efficient compared to the system DGLS or DOLS estimators. Further, the simulation results of Moon and Perron (2005) show that these fully modified estimators suffer more from size distortion than do DGLS or DOLS estimators.

\section{Conclusions}

In this study, we have tested UIP over short-term horizons using the major international currencies. We find that UIP generally holds over a short-term (but above 5-months) horizon for individual and groups of currencies. This finding deviates from findings of other studies. We are using both a different technique and different interest rates. In principle, both differences might explain why our results are different. However, factor analysis shows that the LIBOR rates are defined by only one factor, i.e. domestic interest rates, suggesting that our results are not driven by the use of LIBOR. We are therefore inclined to conclude that the technique we have adopted is the main reason why our results are different from previous studies.

Our result that UIP holds over a short horizon in advanced economies has important implications for researchers and policy makers. Specifically, macroeconomic models used in the central banks of advanced and emerging economies employ UIP to develop linkages with foreign economies. In the absence of strong empirical support in favor of this theory, the confidence of the policy makers on the performance of these macro models remains weak. The findings of our paper thus provide the necessary support for them. Further, the results of this article are likely to improve the exchange rate forecasting ability of researchers. 


\section{References}

Alper, C. E., Ardic, O. P., \& Fendoglu, S. (2009). The economics of the uncovered interest parity condition for emerging markets. Journal of Economic Surveys, 23(1), 115-138.

Baillie, R. T., \& Bollerslev, T. (2000). The forward premium anomaly is not as bad as you think. Journal of International Money and Finance, 19(4), 471488.

Baldwin, R. E. (1990). Re-interpreting the failure of foreign exchange market efficiency tests: small transaction costs, big hysteresis bands (No. w3319). National Bureau of Economic Research.

Baillie, R. T., \& Kilic, R. (2006). Do asymmetric and nonlinear adjustments explain the forward premium anomaly? Journal of International Money and Finance, 25(1), 22-47.

Bansal, R. (1997). An exploration of the forward premium puzzle in currency markets. The Review of Financial Studies, 10(2), 369-403.

Bansal, R., \& Dahlquist, M. (2000). The forward premium puzzle: Different tales from developed and emerging economies. Journal of International Economics, 51(1), 115-144.

Bekaert, G., \& Hodrick, R. J. (1993). On biases in the measurement of foreign exchange risk premiums. Journal of International Money and Finance, 12(2), 115-138.

Bekaert, G., \& Hodrick, R. J. (2001). Expectations hypotheses tests. The Journal of Finance, 56(4), 1357-1394.

Bekaert, G., Wei, M., \& Xing, Y. (2007). Uncovered interest rate parity and the term structure. Journal of International Money and Finance, 26(6), 10381069.

Beyaert, A., García-Solanes, J., \& Pérez-Castejón, J. J. (2007). Uncovered interest parity with switching regimes. Economic Modelling, 24(2), 189-202.

Brueggemann, R., \& Luetkepohl, H. (2005). Uncovered interest rate parity and the expectations hypothesis of the term structure: empirical results for the US and Europe. Applied Economics Quarterly, 51, 143-154. 
Carlson, J.A., Osler, C.L., (1999). Determinants of currency premiums. Mimeo, Federal Reserve Bank of New York.

Carvalho, J. V., Sachsida, A., Loureiro, P. R., \& Moreira, T. B. S. (2004, November). Uncovered interest parity in Argentina, Brazil, Chile, and Mexico: A unit root test application with panel data. In Review of Urban $\mathcal{E}$ Regional Development Studies: Journal of the Applied Regional Science Conference (Vol. 16, No. 3, pp. 263-269). Oxford, UK and Boston, USA: Blackwell Publishing, Inc.

Chaboud, A. P., \& Wright, J. H. (2005). Uncovered interest parity: It works, but not for long. Journal of International Economics, 66(2), 349-362.

Cheung, Y. W., \& Lai, K. S. (1993). Long-run purchasing power parity during the recent float. Journal of International Economics, 34(1-2), 181-192.

Chinn, M.D., 2007. Interest rate parity 4. Entry written for Princeton Encyclopedia of the World Economy.

Chinn, M. D., \& Meredith, G. (2004). Monetary policy and long-horizon uncovered interest parity. IMF Staff Papers, 51(3), 409-430.

Chinn, M. D., \& Quayyum, S. (2012). Long horizon uncovered interest parity reassessed (No. w18482). National Bureau of Economic Research.

Dornbusch, R. (1976). Expectations and exchange rate dynamics. Journal of Political Economy, 84(6), 1161-1176.

Dumas, B. (1992). Dynamic equilibrium and the real exchange rate in a spatially separated world. The Review of Financial Studies, 5(2), 153180.

Engel, C. (1996). The forward discount anomaly and the risk premium: A survey of recent evidence. Journal of Empirical Finance, 3(2), 123-192.

Ferreira, A.L., Leon-Ledesma, M., 2007. Does the real interest rate parity hold? Evidence for emerging and developing countries. Journal of International Money and Finance, 26, 364-382.

Flood, R. P., Rose, A.K., 1996. Fixes: Of the forward discount puzzle. The Review of Economics and Statistics, 78, 748-752. 
Flood, R., \& Rose, A. (2001). Uncovered interest parity in crisis: The interest rate defense in the 1990s. International Monetary Fund (No. 01/207). Working Paper.

Frankel, J., \& Poonawala, J. (2010). The forward market in emerging currencies: Less biased than in major currencies. Journal of International Money and Finance, 29(3), 585-598.

Frenkel, J. A., \& Rodriguez, C. A. (1982). Exchange rate dynamics and the overshooting hypothesis. Staff Papers, 29(1), 1-30.

Froot, K.A., Thaler, R.H., 1990. Anomalies: Foreign exchange. Journal of Economic Perspectives, 4, 179-192.

Harri, A., Brorsen, B.W., 2009. The overlapping data problem. Quantitative and Qualitative Analysis in Social Sciences, 3(3), 78-115.

Harvey, J. T. (2004). Deviations from uncovered interest rate parity: A Post Keynesian explanation. Journal of Post Keynesian Economics, 27(1), 19-35.

Huisman, R., Koedijk, K., Kool, C., \& Nissen, F. (1998). Extreme support for uncovered interest parity. Journal of International Money and Finance, 17(1), 211-228.

Ichiue, H., \& Koyama, K. (2011). Regime switches in exchange rate volatility and uncovered interest parity. Journal of International Money and Finance, 30(7), 1436-1450.

Isard, M. P. (2006). Uncovered interest parity (No. 6-96). International Monetary Fund.

Ismailov, A., \& Rossi, B. (2018). Uncertainty and deviations from uncovered interest rate parity. Journal of International Money and Finance, 88, 242-259.

Johansen, S. (1995). Likelihood-based inference in cointegrated vector autoregressive models. Oxford University Press on Demand.

Juselius, K., \& MacDonald, R. (2004). International parity relationships between the USA and Japan. Japan and the World Economy, 16(1), 17-34.

Kalyvitis, S., \& Skotida, I. (2010). Some empirical evidence on the effects of US monetary policy shocks on cross exchange rates. Quarterly Review of Economics and Finance, 50(3), 386-394. 
Kilian, L., \& Taylor, M. P. (2003). Why is it so difficult to beat the random walk forecast of exchange rates? Journal of International Economics, 60(1), 85-107.

Krishnakumar, J., \& Neto, D. (2008). Testing uncovered interest rate parity and term structure using multivariate threshold cointegration. In Computational Methods in Financial Engineering, 191-210. Springer, Berlin, Heidelberg.

Krugman, P. R. (1991). Target zones and exchange rate dynamics. The Quarterly Journal of Economics, 106(3), 669-682.

Lyons, R.K., 2001. The microstructure approach to exchange rates. MIT Press, Cambridge (MA).

MacDonald, R., \& Taylor, M. P. (1992). Exchange rate economics: A survey. IMF Staff Papers, 39(1), 1-57.

Mark, N. C., \& Wu, Y. (1998). Rethinking deviations from uncovered interest parity: The role of covariance risk and noise. The Economic Journal, 108(451), 1686-1706.

McCallum, B. T. (1994). A reconsideration of the uncovered interest parity relationship. Journal of Monetary Economics, 33(1), 105-132.

Michaud, F.L., Upper, C., 2008. What drives interbank rates? Evidence from Libor Panel. BIS Quarterly Review, 47-58.

Moon, H. R., \& Perron, B. (2005). Efficient estimation of the seemingly unrelated regression cointegration model and testing for purchasing power parity. Econometric Reviews, 23(4), 293-323.

Omer, M., J. de Haan and B. Scholtens, (2014). Testing uncovered interest rate parity using LIBOR. Applied Economics, 46(30), 3708-3723.

Newey, W. K., \& West, K. D. (1994). Automatic lag selection in covariance matrix estimation. The Review of Economic Studies, 61(4), 631-653.

Palm, F. C., Smeekes, S., \& Urbain, J. P. (2011). Cross-sectional dependence robust block bootstrap panel unit root tests. Journal of Econometrics, 163(1), 85-104. 
Sercu, P., Wu, X., 2000. Uncovered interest arbitrage and transaction costs: Errors in variables versus hysteresis effects. Unpublished Working Paper, University of Leuven and City University of Hong Kong.

Tang, K. B. (2011). The precise form of uncovered interest parity: A heterogeneous panel application in ASEAN-5 countries. Economic Modelling, 28(1-2), 568-573.

Weber, E. (2011). What happened to the transatlantic capital market relations? Economic Modelling, 28(3), 877-884.

Westerlund, J. (2007). Testing for error correction in panel data. Oxford Bulletin of Economics and Statistics, 69(6), 709-748. 
Appendix

Table A1: Correlation Between (First Differenced) Interest Rate
Differential Series

\begin{tabular}{lcccccc}
\hline & Euro & JPY & GBP & AUD & CAD & CHF \\
\hline & Panel A: Full Sample differential vis-à-vis US interest rate & \\
\hline Euro & 1.00 & 0.81 & 0.72 & 0.64 & 0.51 & 0.82 \\
JPY & 0.81 & 1.00 & 0.58 & 0.64 & 0.54 & 0.76 \\
GBP & 0.72 & 0.58 & 1.00 & 0.62 & 0.35 & 0.66 \\
AUD & 0.64 & 0.64 & 0.62 & 1.00 & 0.55 & 0.63 \\
CAD & 0.51 & 0.54 & 0.35 & 0.55 & 1.00 & 0.49 \\
CHF & 0.82 & 0.76 & 0.66 & 0.63 & 0.49 & 1.00 \\
\hline Panel B: Full Sample Japanese and Swiss & interest rates differential vis-à-vis US interest rate \\
\hline Euro & 1.00 & -0.81 & 0.72 & 0.65 & 0.51 & -0.83 \\
JPY & -0.81 & 1.00 & -0.59 & -0.64 & -0.54 & 0.76 \\
GBP & 0.72 & -0.59 & 1.00 & 0.62 & 0.36 & -0.66 \\
AUD & 0.65 & -0.64 & 0.62 & 1.00 & 0.55 & -0.64 \\
CAD & 0.51 & -0.54 & 0.36 & 0.55 & 1.00 & -0.49 \\
CHF & -0.83 & 0.76 & -0.66 & -0.64 & -0.49 & 1.00 \\
\hline
\end{tabular}

Source: Authors' Calculations.

Note: This table shows the correlation structure between first differenced, currency specific 6-months interest rate differential series. In Panel A, 6-months interest rate differential series are calculated by subtracting the US Dollar interest rate from other currency interest rate. In Panel B, similar procedure applied for all currencies specific interest rates except for the Japanese yen and the Swiss franc. For these two interest rates, the home currency interest rate is subtracted from the US dollar interest rate.

Table A2: Block Bootstrap Panel Unit Root (Pooled) Tests

\begin{tabular}{lrrrrrrr}
\hline & \multicolumn{2}{c}{ Exchange Rate Differential Series } & & \multicolumn{2}{c}{ Interest Rate Differential Series } \\
\cline { 2 - 4 } \cline { 7 - 8 } & Statistics & 5 percent CV & P-value & & Statistics & 5 percent CV & P-value \\
\hline 1-week & -314.2310 & -17.3620 & 0.0000 & & -3.5450 & -15.5530 & 0.8620 \\
2-week & -165.2870 & -21.6920 & 0.0000 & & -2.6540 & -12.2880 & 0.8350 \\
1-month & -69.3440 & -19.1670 & 0.0000 & & -1.9500 & -8.8460 & 0.7700 \\
2-month & -31.8960 & -13.1120 & 0.0000 & & -2.0830 & -7.4430 & 0.6580 \\
3-month & -19.1860 & -10.8160 & 0.0010 & & -2.2100 & -7.3500 & 0.6150 \\
4-month & -12.5510 & -11.1170 & 0.0260 & & -2.1400 & -6.7300 & 0.6070 \\
5-month & -7.8380 & -10.7360 & 0.1810 & & -2.1010 & -6.4420 & 0.6100 \\
6-month & -6.4250 & -10.2620 & 0.2970 & & -2.1020 & -6.3700 & 0.6160 \\
7-month & -6.0270 & -10.7850 & 0.3780 & & -2.0820 & -6.4310 & 0.6300 \\
8-month & -5.2530 & -10.9910 & 0.5160 & & -2.0470 & -6.5030 & 0.6520 \\
9-month & -5.8730 & -11.0590 & 0.4550 & & -2.0340 & -6.5780 & 0.6680 \\
10-month & -5.6170 & -12.1350 & 0.5570 & & -2.0300 & -6.6670 & 0.6810 \\
11-month & -5.5700 & -11.7170 & 0.5140 & & -2.0610 & -6.8220 & 0.6920 \\
12-month & -5.9860 & -11.8480 & 0.4570 & -2.0800 & -6.9580 & 0.7050 \\
\hline
\end{tabular}

Source: Authors' Calculations.

Note: Estimated test statistics for equation (5) at level of exchange rate and interest rate differential series. 5 percent $C V$ indicates robust critical values calculated at 5 percent level of significance. Pvalues indicate the corresponding probability values of the calculated test statistics. 
Table A3: Results of Westerlund Cointegration Test (Pooled Test)

\begin{tabular}{lrrrrrrr}
\hline & \multicolumn{3}{c}{$\boldsymbol{P t}$} & & \multicolumn{3}{c}{$\boldsymbol{P a}$} \\
\cline { 2 - 4 } \cline { 6 - 8 } & Value & Z-value & Rob. P-value & Value & Z-value & Rob. P-value \\
\hline 6-month & -5.176 & -3.3630 & 0.0040 & & -11.0840 & -8.5090 & 0.0000 \\
7-month & -4.1930 & -2.5210 & 0.0140 & & -8.3780 & -6.2200 & 0.0020 \\
8-month & -4.1160 & -2.4550 & 0.0360 & & -7.7080 & -5.6530 & 0.0040 \\
9-month & -4.1840 & -2.5140 & 0.0280 & & -7.2070 & -5.2290 & 0.0060 \\
10-month & -4.1150 & -2.4540 & 0.0160 & & -6.8010 & -4.8850 & 0.0080 \\
11-month & -3.5320 & -1.9550 & 0.0640 & & -5.4740 & -3.7630 & 0.0240 \\
12-month & -3.4090 & -1.8490 & 0.0620 & -5.1820 & -3.5160 & 0.0160 \\
\hline
\end{tabular}

Source: Authors' Calculations.

Note: Estimates of ECM coefficient based on equation (7). The alternative hypothesis of these test statistics are the cointegration relationship exists when the panel taken as whole. 5 and 12 are the maximum number of leads and lags considered for estimation. Values give the estimated values of the coefficients and Z-values are their standardized values. Rob. Pvalues are the robust probability values calculated using the bootstrap technique. The corresponding values show the level of significance.

\section{Table A4: Estimation Results for System DGLS (Monthly Data)}

\begin{tabular}{lrrrrrrr}
\hline & \multicolumn{1}{c}{$\mathbf{6 - \mathbf { m }}$} & \multicolumn{1}{c}{$\mathbf{7 - \mathbf { m }}$} & \multicolumn{1}{c}{$\mathbf{8 - \mathbf { m }}$} & \multicolumn{1}{c}{$\mathbf{9 - \mathbf { m }}$} & \multicolumn{1}{c}{$\mathbf{1 0 - \mathbf { m }}$} & \multicolumn{1}{c}{$\mathbf{1 1 - \mathbf { m }}$} & \multicolumn{1}{c}{$\mathbf{1 2 - \mathbf { m }}$} \\
\hline Euro & -0.2891 & 0.1103 & 2.8782 & 0.8791 & -0.7631 & $17.0376^{*}$ & $21.8353^{*}$ \\
& 2.3187 & 3.0917 & 2.8813 & 2.9739 & 6.5479 & 4.3569 & 4.8998 \\
JPY & $-3.4596^{*}$ & -0.2399 & 1.1653 & 1.8085 & $-2.8062^{* *}$ & -1.4989 & 0.8416 \\
& 2.0816 & 2.2002 & 1.6906 & 1.6871 & 2.1245 & 2.0517 & 2.5742 \\
GBP & -0.2934 & -0.1913 & 1.9738 & -1.1612 & $-6.5941^{*}$ & $-3.1139^{* *}$ & 1.5832 \\
& 1.6146 & 1.8934 & 1.568 & 1.7073 & 3.1399 & 2.3495 & 2.7434 \\
AUD & -0.7196 & -0.1402 & 0.9967 & 2.8111 & 0.8597 & 2.5259 & 1.5688 \\
& 1.8027 & 1.4448 & 1.5513 & 1.4736 & 1.9878 & 1.7369 & 2.3275 \\
CAD & 1.5326 & -0.0836 & $-4.0469^{*}$ & $-1.9124^{* *}$ & $5.3586^{* *}$ & 0.7959 & -2.4556 \\
& 1.8467 & 2.066 & 2.0445 & 1.5508 & 2.3028 & 1.7798 & 2.3412 \\
CHF & -3.3382 & -4.6011 & $-8.2813^{*}$ & $-5.3422^{*}$ & $-6.0788^{*}$ & 0.6033 & $6.1701^{*}$ \\
& 3.8133 & 4.3311 & 2.8784 & 2.2252 & 2.485 & 1.6825 & 2.0713 \\
\hline Wald Stats & 11.4885 & 4.1313 & 10.0425 & 7.8104 & 12.738 & 10.1588 & 6.5247 \\
Wald p & 0.0744 & 0.6589 & 0.1229 & 0.2523 & 0.0474 & 0.1181 & 0.3670 \\
\hline
\end{tabular}

Source: Authors' Calculations.

Note: Estimates of System DGLS coefficient based on equation (7) using average monthly data with maximum leads and lags of 4 months. The optimal lag length selected using Bayesian Information Criteria (BIC). The null hypothesis is individual coefficient is unity. The figure in italics shows the standard errors. The Null hypothesis for the Wald test is the joint beta coefficient is unity. Wald $\mathrm{P}$ shows the P-values of the Wald test statistics. The symbols indicates $*,<5$ percent and ${ }^{* *}<10$ percent level of significance, respectively. 
Table A5: Estimation Results for System DOLS (SDOLS)

\begin{tabular}{lrrrrrrr}
\hline & $\mathbf{6 - m}$ & \multicolumn{1}{c}{ 7-m } & \multicolumn{1}{c}{ 8-m } & \multicolumn{1}{c}{ 9-m } & 10-m & 11-m & \multicolumn{1}{c}{ 12-m } \\
\hline Euro & & \multicolumn{7}{c}{ System DOLS } & & & \\
& -0.278 & 2.4236 & 3.5999 & 4.7121 & $6.152^{* *}$ & $8.3515^{*}$ & $9.7004^{* *}$ \\
JPY & 2.0146 & 2.1105 & 2.7217 & 2.8512 & 2.7927 & 3.7077 & 4.5603 \\
& -0.7075 & $-1.048^{* *}$ & -1.1609 & -1.1378 & -0.7956 & -0.6515 & -1.0312 \\
GBP & 1.2539 & 1.1603 & 1.3721 & 1.3674 & 1.4037 & 1.7217 & 1.9135 \\
& -0.6000 & -0.1023 & -0.6930 & -0.4170 & -0.6122 & 0.8814 & 3.7240 \\
AUD & 1.7103 & 1.5082 & 1.9771 & 2.0987 & 1.8826 & 2.4351 & 2.7847 \\
& -0.9933 & -0.9490 & -0.5355 & -0.5590 & -0.6936 & -0.7358 & 0.9697 \\
CAD & 1.2610 & 1.6110 & 2.2190 & 2.0494 & 1.8770 & 2.2867 & 2.6355 \\
& 0.0444 & -0.3957 & -0.9880 & $-2.2319^{* *}$ & $-2.2188^{* *}$ & $-3.0872^{* *}$ & $-3.9464^{* *}$ \\
CHF & 1.4682 & 1.7028 & 2.0284 & 1.8667 & 1.7915 & 2.1988 & 2.7878 \\
& -1.4158 & $-4.0798^{*}$ & $-3.2265^{*}$ & -2.1787 & -1.8461 & -1.2688 & -0.1325 \\
& 2.6703 & 2.2338 & 2.5293 & 2.4684 & 2.0253 & 2.3883 & 2.5069 \\
\hline Wald Stats & 12.2551 & 13.6237 & 11.5634 & 14.5290 & 13.6779 & 9.6855 & 7.6626 \\
Wald p & 0.0565 & 0.0341 & 0.0724 & 0.0243 & 0.0334 & 0.1385 & 0.2639 \\
\hline
\end{tabular}

Source: Authors' Calculations.

Note: Estimates of System DOLS coefficient using average weekly data with maximum leads and lags of 12 weeks. The optimal lag length selected using Bayesian Information Criteria (BIC). The null hypothesis is individual coefficient is unity. The figure in italics shows the standard errors. The Null hypothesis for the Wald test is the joint beta coefficient is unity. Wald $\mathrm{P}$ shows the P-values of the Wald test statistics. The symbols indicates ${ }^{*},<5$ percent and $^{* *}<10$ percent level of significance, respectively.

Table A6: Estimation Results for Fully Modified GLS (FMGLS)

\begin{tabular}{lrrrrrrr}
\hline & \multicolumn{1}{c}{ 6-m } & \multicolumn{1}{c}{ 7-m } & \multicolumn{1}{c}{ 8-m } & \multicolumn{1}{c}{ 9-m } & \multicolumn{1}{c}{ 10-m } & \multicolumn{1}{c}{ 11-m } & \multicolumn{1}{c}{ 12-m } \\
\hline Euro & $-0.1343^{*}$ & $-0.1009^{*}$ & $-0.2798^{*}$ & $-0.2166^{* *}$ & 0.9372 & 0.9682 & 2.0269 \\
& 0.3910 & 0.4133 & 0.5771 & 0.6671 & 0.6569 & 0.7542 & 0.8333 \\
JPY & $-2.5297^{*}$ & $-1.9882^{*}$ & $-2.6277^{*}$ & $-2.9759^{*}$ & $-3.1833^{*}$ & $-3.018^{*}$ & $-3.3997^{*}$ \\
& 0.7423 & 0.6328 & 0.7704 & 0.7519 & 0.7710 & 0.9044 & 1.0604 \\
GBP & $-2.7716^{*}$ & $-2.9399^{*}$ & $-3.4442^{*}$ & $-2.9375^{*}$ & $-1.594^{*}$ & $-1.1135^{*}$ & -0.6979 \\
& 0.8325 & 0.8597 & 0.9831 & 0.9786 & 1.0246 & 1.0299 & 1.1889 \\
AUD & $-1.6014^{*}$ & $-1.957^{*}$ & $-2.1516^{*}$ & $-2.059^{*}$ & $-1.1999^{*}$ & $-1.4672^{*}$ & -0.2616 \\
& 0.5065 & 0.5582 & 0.7257 & 0.7719 & 0.7692 & 0.8853 & 0.9032 \\
CAD & 0.6367 & 1.2165 & 0.5112 & 0.6486 & $-0.8737^{*}$ & -0.0695 & -0.3639 \\
& 0.7251 & 0.8215 & 0.8769 & 0.9564 & 0.9486 & 1.0073 & 1.1083 \\
CHF & $-0.0669^{*}$ & $0.0167^{* *}$ & -0.0223 & 0.1068 & $-1.5258^{*}$ & $-1.9338^{*}$ & $-2.948^{*}$ \\
& 0.5270 & 0.5661 & 0.6754 & 0.8305 & 0.8261 & 0.9489 & 0.8932 \\
\hline
\end{tabular}

Source: Authors' Calculations.

Note: System fully Modified GLS (FMGLS) estimates on average weekly data with maximum leads and lags of 12 weeks. The optimal lag length selected using Bayesian Information Criteria (BIC). The null hypothesis is individual coefficient is unity. The figure in italics shows the standard errors. The symbols indicates $*,<5$ percent and ${ }^{* *}<10$ percent level of significance, respectively. 